\title{
How to Do a Peer Review?
}

\begin{abstract}
"The Nobel laureate for literature of this year has said that an author can do anything as long as his readers believe him.A scientist cannot do anything that is not checked and rechecked by scientists of this network before it is accepted."
\end{abstract}

Sune Bergström, Swedish Biochemist (1916-2004).

\subsection{What Is Peer Review?}

Peer review is a process in which a paper's validity, originality and academic content are checked prior to publication in a good journal. In other words, it is 'evaluation of work by one or more people with similar competencies'. The people who carry out this work are called reviewers or referees [1].

The science in a manuscript should be good enough for it to be published. Bad science even with good statistics should not be accepted. The peer-review process is also called the 'art of trashing a paper' as it has been said that $99 \%$ of scientific literature belongs to the waste paper bin [2]. In 1979, Dr. Stephen Lock, the editor of the British Medical Journal wrote, 'few things are more dispiriting to a medical editor than having to reject a paper based on a good idea but with irremediable flaws in the methods used'.

\subsection{How Is a Peer Review Process Initiated?}

After a paper has been submitted, the editors have the first read and check if the manuscript is suitable for the journal. Only if they feel that the science in the article is worth publishing does it undergo the process of peer review (Fig. 32.1). 
1. Scientists study something.

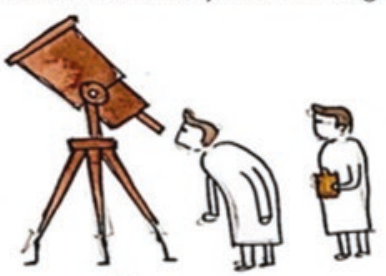

\section{THE PEER \\ REVIEW \\ PROCESS}

3. Journal editor receives an article and sends it out for peer review.
4. Peer reviewers read the article and provide feedback to the editor.

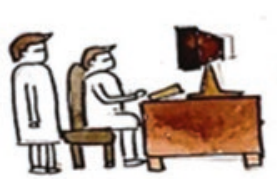

2. Scientists write their results
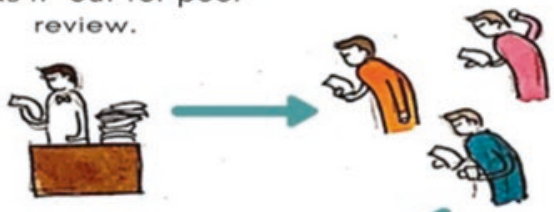

5. If an article finally meets editorial \& peer standards it is a published in a journal.

Fig. 32.1 The peer review process

\subsection{What Are the Qualities of a Good Peer Reviewer?}

The reviewer is like a traffic policeman who regulates the science in a journal. He becomes involved in peer review due to his academic and altruistic bent, to improve his curriculum vitae, to be involved in editorial work and to be informed about the field of research before anyone else. He should be aware of the journal's style and stance. An editor often takes the help of the expertise of the members of his editorial board for the peer review process.

The qualities of a good reviewer are:

- To give a judicious and professional review.

- To critique the science in the manuscript.

- To review the article in the stipulated time.

- To suggest changes that might improve the quality of the paper.

- To give a balanced judgement on whether the paper should be accepted, revised or rejected.

- He should have the ability to express complex ideas simply.

Referees who have a sound grasp of epidemiology and statistics are sometimes more likely to produce good reviews. Also, those who spend a longer time over their 
task tend to produce better reviews [3]. An interesting study suggested that reviewers who had a lower academic or professional status provided a better analysis of manuscripts than those of higher status possibly because they were less busy and being invited to do this task by a reputed journal added to their academic credentials. They were also less likely to refuse to review. If they were less than 40 years old they were also likely to produce more useful comments [4].

A reviewer is not expected to correct poor English grammar or syntax which can be done by the editorial team or the publishers. They can help by underlining sentences or paragraphs and writing 'rephrase', 'unclear' or 'unsubstantiated'.

\subsection{What Are the Types of Peer Review Process?}

The process can be a single, double- or even triple-blind review or an open review process $[5,6]$.

Single-blind peer review - this is the commonest type of review in which the names of the authors are concealed from the reviewer. The concealed identity allows for neutral decisions as a reviewer will not be influenced by the names or institutions of the authors. The only concern is that if the reviewer is also from the same specialty, he may delay the process, to give himself a chance to publish earlier. Occasionally, a referee may sometimes use his concealment to be unnecessarily critical or harsh when judging an author's work.

Double-blind peer review - in this both the referee and the author are concealed from each other. There are several advantages of this model. Author concealment restricts the reviewer's bias and a more authentic opinion may be given. Manuscripts written by respected professional colleagues or famous authors can be considered on the basis of their merit rather than the person's standing in the profession. However, often the reviewer's or author's identity cannot be concealed as there is some mention of him in the methodology section, or it becomes obvious from the style of writing or the scientific content.

A triple-blind review is a process in which the reviewers as well as the authors are unknown to the editor. The submitted articles are processed and handled in such a way as to minimize any potential bias towards the author(s). However, this is a complicated process compared to a double-blind review. There is also the possibility that the editor and/or reviewers may correctly opine the author's identity from their style of writing or the methodology used in the investigation.

Open review is a general term for many different models directed at better transparency during the peer review process. The most common type of open review is when both the referee and author are known to each other. Other types of open peer review consist of the publication of the referees' names on the article's printed page. The ultimate degree of openness would be the publication of the peer review data together with the article, the peer review reports (signed or anonymous) along with the authors' and editors' responses alongside the article and publication of the manuscript after opening a discussion forum to the readers along with comments (named or anonymous). Open review has gained impetus since the late 1990s, with the decision of the British Medical Journals (BMJ) to publish both reviewers' names and reviews [7]. 


\subsection{What Are the Top Ten Causes Why a Paper Gets Rejected?}

The peer review process is slow but is necessary to keep up the standard of the journal. The top causes for rejection during the process are enumerated below: $[8,9]$.

1. The research question is not clear or buried somewhere or not mentioned in the manuscript.

2. The main scientific issue has not been addressed properly.

3. The work submitted is not original or a duplication of the work of others and does not add to scientific knowledge.

4. The study design is not appropriate.

5. The sample size is not adequate for any statistically significant results.

6. The methodology for the study is not appropriate.

7. The statistical methods used are not appropriate or have been calculated wrongly.

8. The conclusions drawn are unreasonable or unjustifiable.

9. There is a conflict of interest, the study is sponsored and it seems that the sponsor will benefit from publication.

10. The manuscript is badly written and there are both major scientific and grammatical mistakes.

\subsection{What Are the Top Ten Tips for Doing a Good Peer Review?}

These are easy to remember:

\section{Respond quickly to offers to review}

Read the abstract and full text once and you will be able to judge if this is in your area of interest. Be swift to respond to the call given by the editors.

2. Show Honesty

If you are also working on a similar subject to the paper in question, do inform the editorial about this conflict of interest.

\section{Know the Scope of the journal}

Once the manuscript is in your hand be aware of the journal's style, editorial policy and article presentation.

4. Give constructive suggestions

It is easy to find loopholes in someone else's work. Even if you are rejecting the manuscript give constructive feedback to authors so that they can improve their paper.

5. Assign sufficient time for the review

The comments on the review should not be made in haste. It is always better to spend time to review the manuscript.

6. Number your feedback comments

It is easier for the editors if comments are mentioned in a pointwise fashion. 


\section{Focus on the science in the manuscript}

While reviewing, analyze the science in the manuscript. If the English and syntax are wrong, just mention this in the comments rather than pointing out each mistake.

\section{Read the aims of the study and check if they have been met}

Reading aims and conclusions gives a good idea about what new information the manuscript has added.

\section{Check the statistics}

Editors always welcome reviewers who have a strong statistical background and comment on the sample size and other analytical calculations.

\section{Praise the authors for something novel}

If the paper has extraordinary findings and is well written it is always best to bring this to the notice of the editors. Do not forget to praise the authors for their work.

\subsection{What Are the Guidelines for Peer Reviewers from the Committee on Publication Ethics (COPE)?}

These guidelines are given below: [10].

Initial step: The reviewer should read the main file, supplementary file and also policy statement of the journal. In case there is something missing or any clarification is required the reviewer should not contact the author directly.

Confidentiality: The information gathered from reviewing should not be used by the referee for his own advantage. Do not involve anyone else in the review of a manuscript, without first obtaining permission from the journal The names of any persons who have helped with the review should be included so that they are associated with the manuscript in the journal's records and can also receive due recognition for their efforts.

Bias and competing interests: It is important to remain impartial by thoughts related to the nationality, religious or political beliefs, gender or other characteristics of the authors, origins of a paper or by commercial considerations. If during the process the reviewer feels a competing interest to evaluate the manuscript, to inform the journal office.

Suspicion of ethics violations: If the reviewer feels that there has been wrongdoing with respect to research, ethics and publication he needs to inform the journal office or editors. This should also include similarity in publication, data manipulation or if ethical standards have not been followed.

Transferability of peer review: For this, one needs to understand the term "portable or cascading peer review'. Here the publishing house has a policy for transferring a peer reviewer's comments to other journals in the publisher's portfolio and after permission this can be done. 


\subsection{Does Training Help in Improving the Peer Review Process?}

Logically, the answer should be yes. Having workshops and standardization should help to improve the peer review. In a systematic review and meta-analysis, it was suggested that as compared with the standard peer review process, training did not improve the quality of a peer review report. Also, the use of a checklist did not improve the quality of the final manuscript. However, adding a statistical peer reviewer improved the quality. It was also concluded that blinded peer reviews did not affect the quality of the report or the rejection rate [11].

There has been recently a checklist which has been suggested for the peer-review process [12]. The 20 items to assess peer-review (PR) report quality included in the survey. Few sites also give details about how to peer review the manuscript, how to write peer review report and how-to read manuscript for peer review (Table 32.1). These include plos.org/resources/for-reviewers, https://authorservices.wiley.com/, https://researcheracademy.elsevier.com/ and https://masterclasses.nature.com/

Table 32.1 Twenty-point checkpoints for peer reviewers

\begin{tabular}{l|l}
\hline Labels & Items to assess PR report quality \\
\hline Relevance & The reviewer comments on the relevance of the study \\
\hline Originality & The reviewer comments on the originality of the study \\
\hline Interpretation results & The reviewer comments on the interpretation of study results \\
\hline $\begin{array}{l}\text { Strengths and weaknesses } \\
\text { general) }\end{array}$ & $\begin{array}{l}\text { The reviewer comments on the general strengths and } \\
\text { weaknesses of the study }\end{array}$ \\
\hline $\begin{array}{l}\text { Strengths and weaknesses } \\
\text { (methods) }\end{array}$ & $\begin{array}{l}\text { The reviewer comments on the strengths and weaknesses of } \\
\text { the study methods }\end{array}$ \\
\hline Statistical methods & $\begin{array}{l}\text { The reviewer comments on the appropriateness of the } \\
\text { statistical methods }\end{array}$ \\
\hline Methodological quality & $\begin{array}{l}\text { The reviewer comments on the methodological quality } \\
\text { (internal validity) of the study }\end{array}$ \\
\hline $\begin{array}{l}\text { Applicability and external } \\
\text { validity }\end{array}$ & $\begin{array}{l}\text { The reviewer comments on the applicability and external } \\
\text { validity of the study results }\end{array}$ \\
\hline Presentation and organization & $\begin{array}{l}\text { The reviewer comments on the presentation and organization } \\
\text { of the manuscript }\end{array}$ \\
\hline $\begin{array}{l}\text { Adherence to reporting } \\
\text { guidelines (RG) }\end{array}$ & $\begin{array}{l}\text { The reviewer comments on the adherence of the manuscript } \\
\text { to the reporting guideline }\end{array}$ \\
\hline Structure of reviewer's comms. & The reviewer's comments are structured and organized \\
\hline Clarity & The reviewer's comments are clear and easy to read \\
\hline Constructiveness & The reviewer's comments are constructive \\
\hline Detail/thoroughness & The reviewer's comments are detailed and thorough \\
\hline Objectivity & The reviewer's comments are objective \\
\hline Fairness & The reviewer's comments are fair \\
\hline Support by evidence & The reviewer's comments are evidence based \\
\hline Knowledgeability & $\begin{array}{l}\text { The reviewer knows and understands correctly the content of } \\
\text { the manuscript }\end{array}$ \\
\hline Tone & The reviewer uses a courteous tone \\
\hline Timeliness & The reviewer completes the PR report on time \\
\hline
\end{tabular}




\subsection{What Is the Future of the Peer Review System?}

Like all other processes, the peer review process has also been subjected to criticism. Peer review has often been thought to be an unappreciated job [13, 14]. The lack of motivation and commitment for doing such time-consuming work remains a challenge [15]. Both non-financial [16] and financial incentives have been suggested to improve peer reviewing. The non-financial approach includes giving a subscription to the journal, publishing names on websites, giving a certificate and also providing free and non-limited access to scholarly sites to digital libraries like Scopus, UpToDate, etc.

The financial approach is giving cash for reviewing. The money which is generated from the article processing charges can be shared with the reviewer $[17,18]$. Many feel that this would make publication into a business model. However, we agree with payment because since the only person who is earning money from a printed paper is the publisher the time has come for reviewers to be paid and given more recognition for their expertise and effort (Table 32.2).

\subsection{What Is a Preprint? What Are the New Developments in Preprints?}

A preprint or ahead of print is a full draft of a scientific manuscript that is shared widely in the public domain before it has been certified by the peer-reviewed process. Most preprints are given a digital object identifier (DOI) so that they can be cited in other research papers. In the traditional publication system, the manuscript is sent to two or three reviewers before publication. With a preprint, other scientists can notice the manuscript early and any theoretical flaws pointed out early [19].

Very recently a 'preprint server' was started by Yale University and The BMJ called 'MedRxiv'. This service is for academic manuscripts that have not undergone the process of peer review and have not yet been published. The authors can post papers and receive feedback even before journals review and accept or reject

Table 32.2 Future of peer review system

\begin{tabular}{l|l}
\hline Traditional approach & Suggested approach \\
\hline $\begin{array}{l}\text { Gatekeeping to scientific content published } \\
\text { in journal }\end{array}$ & $\begin{array}{l}\text { No gatekeeping function but only teamwork } \\
\text { and productive criticism }\end{array}$ \\
\hline $\begin{array}{l}\text { Quality control difficult to measure } \\
\text { system }\end{array}$ & Quality control achieved based on consensus \\
\hline $\begin{array}{l}\text { Limited peer review exclusively to 2-3 } \\
\text { people }\end{array}$ & $\begin{array}{l}\text { Oplf-organized reviewer and open system } \\
\text { review matching }\end{array}$ \\
\hline $\begin{array}{l}\text { No incentives for reviewer } \\
\text { Entry into editorial board based on board's } \\
\text { High rate of refusal to review }\end{array}$ & $\begin{array}{l}\text { Incentive for reviewer based on performance } \\
\text { Entry based on reputation in the scientific } \\
\text { community } \\
\text { More persons to be enrolled for the process of } \\
\text { peer review }\end{array}$ \\
\hline
\end{tabular}


them. This is a good development as it allows an open feedback process. Many science journals like Physics and the New England Journal of Medicine ask if this service has been used as it improves the science of the final paper submitted to the journal.

This has been an important way of sharing information during the COVID pandemic, although at times readers and journalists have not distinguished between non-peer-reviewed and peer-reviewed research. Many of the COVID-19related manuscripts were found to be imperfect when posted on MedRxiv (Fig. 32.2) [20].

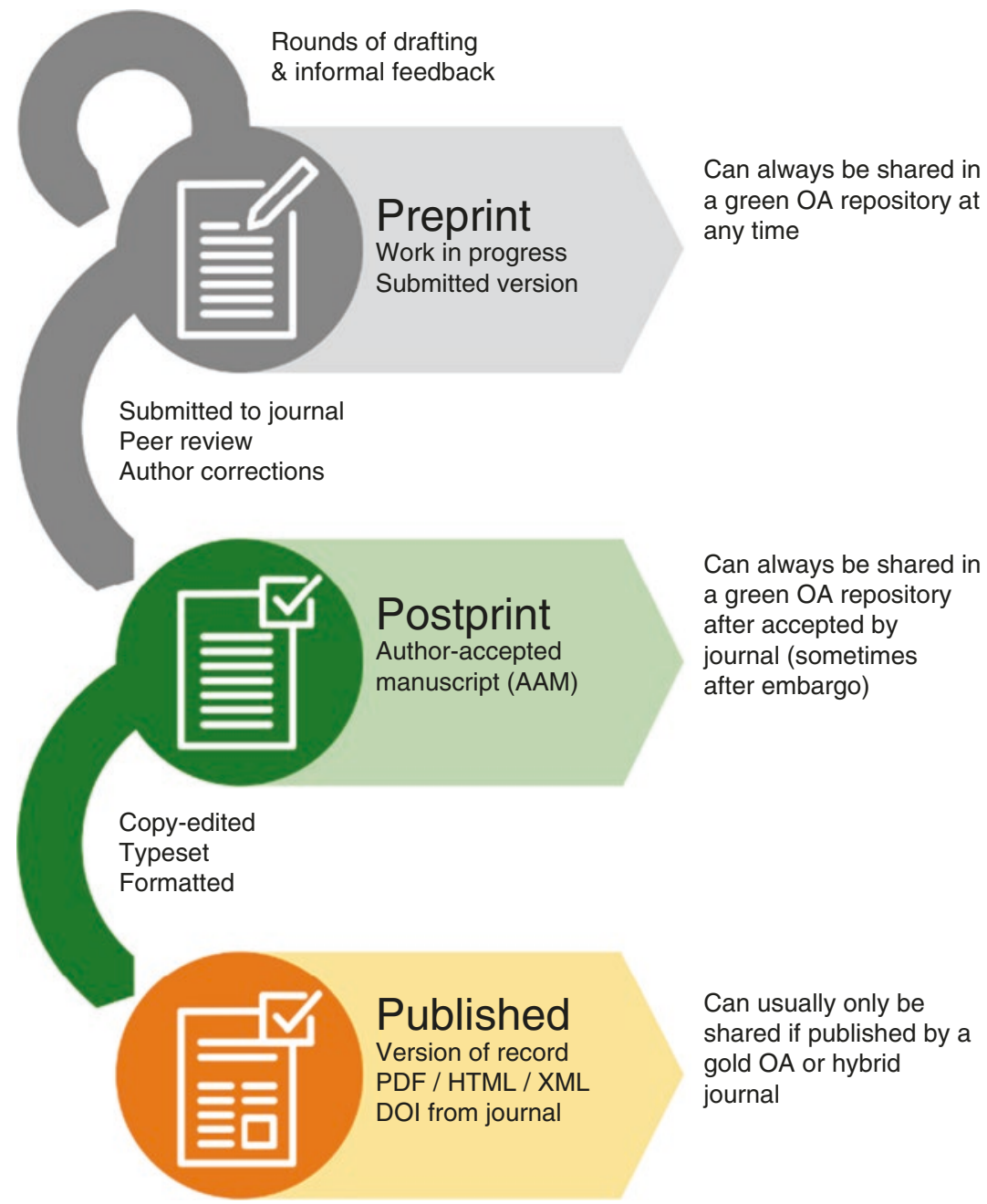

Fig. 32.2 Article publication algorithm 


\subsection{Conclusions}

- The peer review process is a regulatory process for assessing papers that have been offered for publication in a journal.

- Reviewers are like gatekeepers who control the entry of scholarly information.

- The process of peer review has a hierarchical order, i.e., from authors submitting the papers to a journal, to editors forwarding the paper to a reviewer, from the reviewer to the editor and finally the editors passing judgement.

- Preprints increase the visibility of a scientific paper even before the peer review process.

\section{References}

1. Yaddanapudi LN, Yaddanapudi S. An introduction to peer review. J Anaesthesiol Clin Pharmacol. 2015;31:437-9.

2. Getting your bearings: what is this paper about? In: How to read a paper. The basics of evidence-based medicine. Trisha Greenhalgh, 3rd edition, Blackwell Publishing, 2007.

3. Black N, van Rooyen S, Godlee F, Smith R, Evans S. What makes a good reviewer and a good review for a general medical journal? JAMA. 1998;280:231-3.

4. Stossel TP. Reviewer status and review quality: experience of the journal of clinical investigation. N Engl J Med. 1985;312:658-9.

5. Ali PA, Watson R. Peer review and the publication process. Nurs Open. 2016;3:193-202.

6. Horbach SPJMS, Halffman WW. The changing forms and expectations of peer review [published correction appears]. Res Integr Peer Rev. 2018 Nov 14;3:11.

7. Smith R. Opening up BMJ peer review. A beginning that should lead to complete transparency. 1999;318:4-5.

8. Ali J. Manuscript rejection: causes and remedies. J Young Pharm. 2010;1:3-6.

9. Sullivan EJ. Top 10 reasons a manuscript is rejected. J Prof Nurs. 2002;18:1-2.

10. COPE Council. Ethical guidelines for peer reviewers. Last accessed on 20th June2020. Available on www. publicationethics.org.

11. Bruce R, Chauvin A, Trinquart L, Ravaud P, Boutron I. Impact of interventions to improve the quality of peer review of biomedical journals: a systematic review and meta-analysis. BMC Med. 2016;14:85.

12. Barroga E. Innovative strategies for peer review. J Korean Med Sci. 2020;35:e138.

13. Superchi C, Hren D, Blanco D, et al. Development of ARCADIA: a tool for assessing the quality of peer-review reports in biomedical research. BMJ Open. 2020;10(6):e035604.

14. Tennant JP. The state of the art in peer review. FEMS Microbiol Lett. 2018;365(19):fny204.

15. Teixeira da Silva JA. Challenges to open peer review. Online Inf Rev. 2019;43:197-200.

16. Tennant JP, Dugan JM, Graziotin D, Jacques DC, Waldner F, Mietchen D, et al. A multidisciplinary perspective on emergent and future innovations in peer review. F1000 Res. 2017;6:1151.

17. Ahmed HS, Gasparyan AY. Criticism of peer review and ways to improve it. Eur Sci Ed. 2013;39(1):8-10.

18. Steel G, Price A, Seth B, Biswas R, Chatterjee P. Charity is welcome: the international benefits and pitfalls of peer review. Peer J PrePrints. 2016;4:e1585v2.

19. NIH Preprint Pilot FAQs. Last accessed on 12th July2020. Available on https://www.ncbi.nlm. nih.gov/pmc/about/nihpreprints-faq/.

20. The preprint service for health science. Last accessed on 12th July2020. Available on https:// www.medrxiv.org/. 
Open Access This chapter is licensed under the terms of the Creative Commons Attribution 4.0 International License (http://creativecommons.org/licenses/by/4.0/), which permits use, sharing, adaptation, distribution and reproduction in any medium or format, as long as you give appropriate credit to the original author(s) and the source, provide a link to the Creative Commons license and indicate if changes were made.

The images or other third party material in this chapter are included in the chapter's Creative Commons license, unless indicated otherwise in a credit line to the material. If material is not included in the chapter's Creative Commons license and your intended use is not permitted by statutory regulation or exceeds the permitted use, you will need to obtain permission directly from the copyright holder. 